\title{
Production of methane gas hydrate and carbon dioxide from the biogas of MSW landfills for use in the chemical industry
}

\author{
Alexander V. Lukanin, Elena S. Klevanova, Mikhail S. Burka, Artem A. Levin, and Kirill O. \\ Spitsyn \\ Peoples' Friendship University of Russia (RUDN University), 119198 Moscow, Russia
}

\begin{abstract}
The problem of the impact of MSW landfills on the atmosphere is considered. Biogas collection systems were investigated. Modern methods of biogas utilization are analyzed. The technological scheme of processing of gas generated at MSW landfills for the production of gas hydrate from the main macro-components is presented.
\end{abstract}

\section{Introduction}

Landfill as a complex engineering structure, the main element of which is a waste storage array, on the one hand, is designed to provide protection from pollution of the atmosphere, soil, surface and ground water. On the other hand, the waste disposal array functions as a bioreactor, in which biological, chemical and physical processes occur, inevitably accompanied by emissions of pollutants.

At the global level, according to [1], landfills are the third largest source of greenhouse gases in terms of total impact on the atmosphere, the most dangerous of which is methane, emitting about $11 \%$ of the global amount of methane emissions.

In Russia, the disposal of waste in landfills and landfills remains the main method of waste management. According to the Russian Environmental Operator (hereinafter referred to as REO) [2] on the territory of the country, in 2019, 65 million tons of solid municipal waste were generated, 18.2 million tons of MSW were sent for processing ( $28 \%$ of the total volume); during the same period, 4.55 million tons were sent for reuse ( $6 \%$ of the total volume).

After the operation of the landfill map is completed, in order to reduce the negative impact on the environment, passive and active degassing systems are installed, which allow collecting the biogas generated during the decomposition of waste from the landfill body.

An actual method of processing the collected gas in the Moscow region is the production of electricity by means of combustion in generator sets, followed by the disposal of residues in flare installations.

The proposed method will allow us to identify the main macro-components of the resulting biogas for use in the chemical industry. 


\section{Materials and methods}

The main macro component of landfill gas is methane (CH4), its share ranges from 50 to $70 \%$, after passing the technological scheme described below (block diagram), the methane concentration will reach $90-95 \%$, which allows us to consider it as a substitute for natural gas. The second macro component of landfill gas is carbon dioxide $\left(\mathrm{CO}_{2}\right)$, whose share is from 30 to $50 \%$ [3]. The accompanying components are nitrogen $\left(\mathrm{N}_{2}\right)$, oxygen $(\mathrm{O} 2)$, hydrogen $\left(\mathrm{H}_{2}\right)$, and organic compounds of non-methane origin.

The described gas processing technology will allow the use of two main macrocomponents of biogas, which make up $85-95 \%$ of the volume. The products of this technique will be the gas hydrate form of methane and the gas hydrate form of carbon dioxide, which will allow them to be used separately or together as raw materials for the chemical industry, for example, in the steam carbon dioxide conversion of methane for the production of synthesis gas $\left(\mathrm{H}_{2} / \mathrm{CO}\right)$.

The gas-hydrate form of the product with small production volumes will reduce transport costs, since it does not require the laying of pipelines and the creation of expensive infrastructure. The saturation of one $1 \mathrm{~m}^{3}$ of methane gas hydrate in the form of ice is comparable to $\sim 200 \mathrm{~m}^{3}$ of methane. [4]

The current method for processing biogas into electricity at the «Torbeevo» MSW landfill does not use the raw potential of CO2. The disadvantage of the method is the sale of generated electricity at a green tariff, which is not economically feasible.

\section{Results of the study}

The authors of the article developed a technological scheme in which there is a step-by-step purification of biogas from related components and the production of gas hydrate for use in the chemical industry (for example, the production of synthesis gas by steam carbon dioxide conversion of methane) (block diagram).

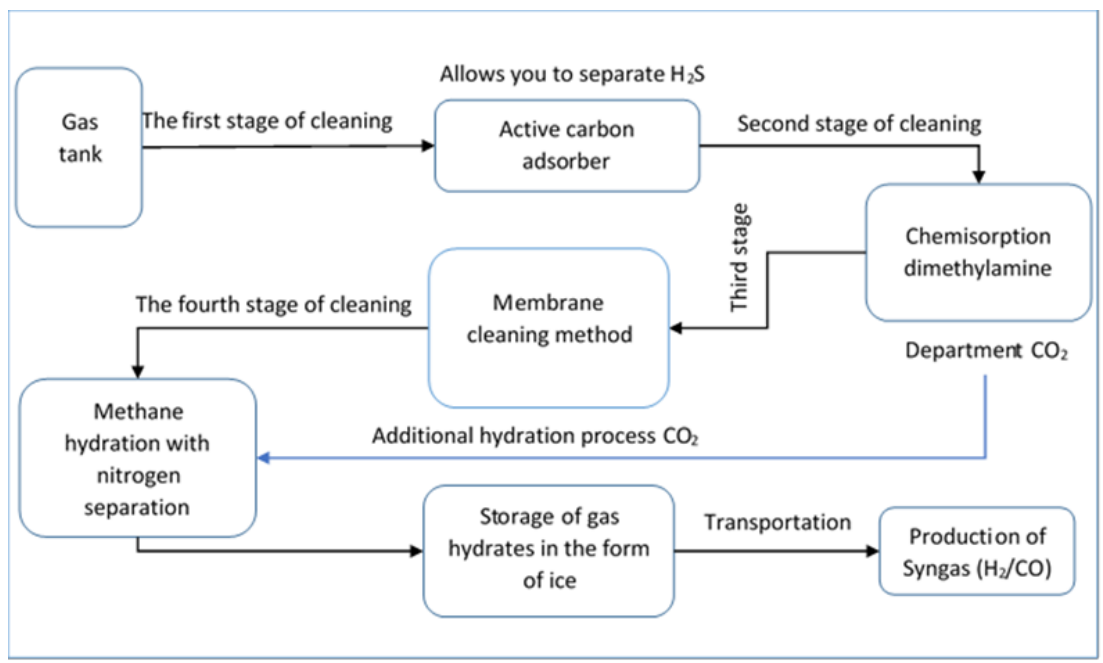

Fig. 1. Block diagram.

Biogas treatment is carried out in four stages.

The first stage is the removal of hydrogen sulfide using activated carbon. This method is used in the chemical industry when working with natural gas. Adsorption rates of up to $99.5 \%$ of hydrogen sulfide are achieved. 
The second stage - Chemisorption-is based on the chemical interaction of CO2 with the active part of the absorbent, which is used as a secondary amine (dimethylamine).

Alkanolamines, being bases, easily react with acid gases to form water-soluble salts. In this case, the following reactions occur:

$$
\begin{gathered}
\mathrm{CO}_{2}+2 \mathrm{C}_{2} \mathrm{H}_{7} \mathrm{NO} \leftrightarrow \mathrm{C}_{2} \mathrm{H}_{7} \mathrm{NO}^{*} \mathrm{H}^{+}+\mathrm{C}_{2} \mathrm{H}_{7} \mathrm{NO}^{*} \mathrm{COO}^{-} \text {(quickly) } \\
\mathrm{CO}_{2}+\mathrm{H}_{2} \mathrm{O} \leftrightarrow \mathrm{H}_{2} \mathrm{CO}_{3} \text { (slowly) } \\
\mathrm{H}_{2} \mathrm{CO}_{3} \leftrightarrow \mathrm{H}^{+}+\mathrm{HCO}_{3}^{-} \text {(quickly) } \\
\mathrm{HCO}_{3}^{-} \leftrightarrow \mathrm{H}^{+}+\mathrm{CO}_{3}^{-} \text {(quickly) } \\
\mathrm{C}_{2} \mathrm{H}_{7} \mathrm{NO}+\mathrm{H}^{+} \leftrightarrow \mathrm{C}_{2} \mathrm{H}_{7} \mathrm{NO}^{*} \mathrm{H}^{+} \text {(quickly) [5] }
\end{gathered}
$$

Secondary amines react with $\mathrm{CO} 2$ to form carbamate (a salt of substituted carbamic acid - amine), carbonate, and bicarbonate amines. At moderate degrees of carbonization of amine (up to $0.5 \mathrm{~mol}$ of $\mathrm{CO} 2 / \mathrm{mol}$ of amine), a rapid reaction of carbamate formation occurs mainly. Carbamates of amines are unstable compounds and in a slightly alkaline environment they slowly decompose to form bicarbonate:

$$
\mathrm{R}_{2} \mathrm{NCOOR}_{2} \mathrm{NH}_{2}+\mathrm{H}_{2} \mathrm{O} \leftrightarrow \mathrm{R}_{2} \mathrm{NH}+\mathrm{R}_{2} \mathrm{NH}_{2} \mathrm{HCO}_{3} \text {, where } \mathrm{R}-\mathrm{ROCH}_{2} \mathrm{CH}_{2}
$$

The reaction product dimethylamine and carbon dioxide are $\left(\mathrm{C}_{2} \mathrm{H}_{5} \mathrm{NH}_{3}\right) \mathrm{HCO}_{3}$ и $\left(\mathrm{C}_{2} \mathrm{H}_{5} \mathrm{NH}_{3}\right) 2 \mathrm{CO}_{3}$.

Which in turn decompose into:

$$
\begin{aligned}
& \left(\mathrm{C}_{2} \mathrm{H}_{5} \mathrm{NH}_{3}\right) \mathrm{HCO}_{3} \rightarrow \mathrm{C}_{2} \mathrm{H}_{5} \mathrm{NH}_{2}+\mathrm{CO}_{2}+\mathrm{H}_{2} \mathrm{O} \\
& \left(\mathrm{C}_{2} \mathrm{H}_{5} \mathrm{NH}_{3}\right) 2 \mathrm{CO}_{3} \rightarrow 2 \mathrm{C}_{2} \mathrm{H}_{5} \mathrm{NH}_{2}+\mathrm{CO}_{2}+\mathrm{H}_{2} \mathrm{O}
\end{aligned}
$$

Thus, due to several successive reactions, it is possible to separate the $\mathrm{CO} 2$ from the other components of the biogas.

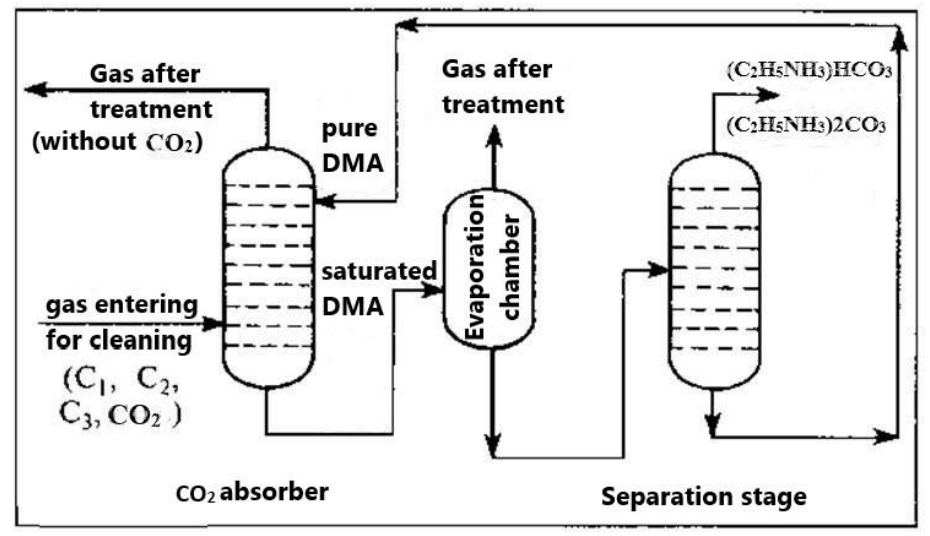

Fig. 1. Structure of the absorber.

The acid gas supplied for cleaning enters the lower part of the absorber. This machine usually contains 20 to 24 plates. An aqueous solution of amine enters the upper part of the absorber. As the solution flows down the plates, it is in contact with the acid gas as the gas moves up through the liquid layer on each plate. When the gas reaches the top of the vessel, virtually all of the $\mathrm{CO} 2$ is removed from the gas stream.

The third stage is the separation of non-methane organic compounds (by the membrane method)

The advantage of the membrane method is that the separation process is carried out without a phase transition, which makes this technology low-energy intensive [6]. 


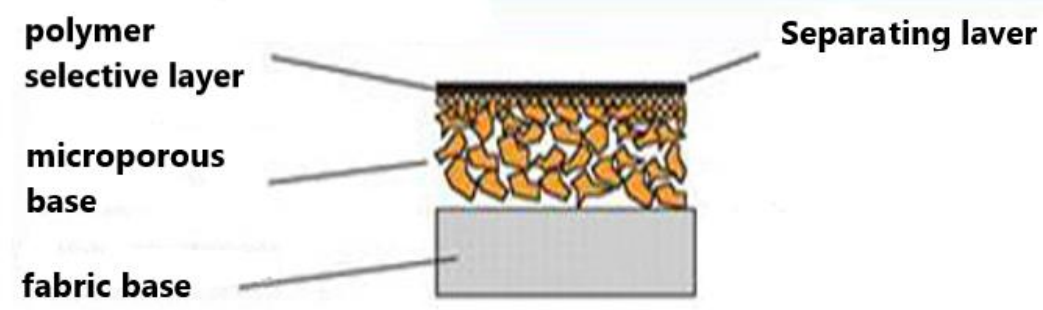

Fig. 2. Transverse section of the membrane.

The elastic membrane allows condensable (compressible) vapors, such as $\mathrm{C}_{3}+$ hydrocarbons and heavier, aromatic hydrocarbons and water, and does not allow noncondensable gases, such as methane, nitrogen and hydrogen [7].

The fourth stage is the separation of methane from nitrogen and the production of methane gas hydrate. Additionally, the production of carbon dioxide gas hydrate in the same reactor, but under different conditions.

The main element of the gas hydration unit is a high-pressure reactor, the required volume, in the case of calculations for the «Torbeevo» MSW landfill of $5 \mathrm{~m}^{3}$.

In the installation, it is necessary to provide a mechanism that sets the movement of the blades to implement the process of mixing the medium in order to intensify the process of hydrate formation. In order to change the temperature parameters during the formation of hydrate, it is necessary to place the reactor in a refrigeration unit with controlled environmental conditions.

The principle of operation of the installation. Biogas from the high-pressure receiver enters the reactor through a gas analyzer, which allows you to calculate the optimal pressure and temperature parameters necessary for the separation of methane and nitrogen. The reactor is pre-filled with water to the required level. To increase the speed of the hydrate formation reaction, up to $3.5 \mathrm{mg} / \mathrm{l}$ of dibutylphenol (surfactant) water is additionally introduced into the water, which reduces the hydrate formation process to 20-25 minutes.

After the gas is injected into the reactor, the mixing process is activated. The end of the hydrate formation process can be determined by the absence of a noticeable pressure drop in the reactor during a given period of time.

Methane-in combination with water, they pass into the form of gas hydrates, and nitrogen remains in a gaseous form $[8,9]$.

After the formation of a liquid form of water with the presence of methane gas hydrate in it, the reactor is cooled, which leads to the transition of water to an ice form [10].

Carbon dioxide is separated from the main gas mixture in the second stage and passes the fourth stage separately, this allows you to reduce capital investment in equipment.

The volume of production of methane gas hydrate and carbon dioxide gas hydrate with a biogas release capacity of 24 thousand tons per year (the estimated figure for the Torbeevo MSW landfill for 2021) will be 125.8 thousand $\mathrm{m}^{3}$ of methane gas hydrate and 25 thousand $\mathrm{m}^{3}$ of carbon dioxide gas hydrate.

\section{Conclusions}

The proposed method makes it possible to use the raw material potential of biogas by 85 $95 \%$ of the volume generated at MSW landfills and minimize the impact on the environment.

In the gas hydrate form, methane and carbon dioxide will make it possible to deliver raw materials over distances of hundreds of kilometers with minimal capital investment. 
The market volume for the sale of natural gas (methane) and carbon dioxide in 2020 amounted to 691 billion $\mathrm{m}^{3}$ and 420 thousand tons, which makes it advisable to produce methane gas hydrate and carbon dioxide gas hydrate from biogas landfills.

\section{References}

1. Global anthropogenic greenhouse gas emissions (other than CO2): 1990-2030, www.epa.gov

2. Annual Report 2019, PPK "Russian Environmental Operator" (2020)

3. T. V. Bliznyukova, Optimization of the location of existing and planned waste management facilities as a factor of sustainable development of urban agglomerations (2021)

4. G. A. Kunsbayeva, Mathematic modeling of gas hydrate processing and synthesis processes in tubular reactors (2016)

5. I. A. Lavrentiev, Industrial technologies for the production of methyl diethanolamine and methyl alcohol esters-new generation absorbers for the purification of natural and process gases from acidic impurities (2004)

6. E. A. Grushevenko, Comb-based polysiloxane membranes for the separation of hydrocarbon gas mixtures (2019)

7. R. W. Baker, Macromolecules, 47 (20) (2014)

8. S. Oddy, Effect of Phase - Contacting Patterns and Operating Conditions on Gas Hydrate Formation (2014)

9. P. Naeiji, F. Varaminian, J. Non - Equilib. Thermodyn (2013)

10. S. Hashemi, A. Macclu and P. Servio, Chem. End. Sci., 64 (19) (2009) 